\title{
Judicialização da educação de surdos: caminho para sua efetivação?
}

\author{
Judicialization of deaf education: \\ the path towards effectiveness?
}

\section{Legalización de la educación de sordos: ¿camino para su efectividad?}

\author{
Cássia Sígolo Rodrigues ${ }^{2}$ \\ Ana Elisa Spaolonzi Queiroz Assis ${ }^{3}$
}

\begin{abstract}
Resumo: Este artigo buscou analisar os encaminhamentos referentes à judicialização de políticas educacionais já definidas, mas não implementadas, aos estudantes surdos em municípios do Estado de São Paulo, a partir do levantamento de decisões proferidas pelo Tribunal de Justiça de São Paulo, no período de 2005 a 2018. De posse das nove ementas, foi concebido que em cinco delas a tônica dos depoentes foi a garantia do direito da presença do profissional Tradutor e Intérprete de Língua Brasileira de Sinais (TILS) no processo de escolarização de estudantes surdos. Observou-se que os acórdãos consolidaram a oferta do TILS como um direito deste alunado, e foram prontamente atendidas em primeira instância. Apesar da legislação vigente, a busca pela efetivação de um direito proclamado, mas não cumprido, foi executada por meio da judicialização.
\end{abstract}

Palavras-chave: Judicialização. Educação de surdos. Direito à educação.

Abstract: This article sought to analyze the referrals referring to the judicialization of educational policies already defined, but not implemented, for deaf students in municipalities in the State of São Paulo, based on the decision taken by the Court of Justice of São Paulo among 2005 and 2018. With the possession of the nine actions resume, it was conceived that in five of them the tonic of the deponents was the guarantee of the presence of the professional Translator and Interpreter of Brazilian Sign Language (TILS) in the process of schooling of deaf students. It was noted that the judgments consolidated TILS's offer as a right of the latter and were promptly served at first instance. Despite the current legislation, the search for the enforcement of a proclaimed but unfulfilled right was executed through the judicialization.

Keywords: Judicialization. Deaf education. Education rights.

Resumen: Este artículo buscó analizar los encaminamientos referentes a la judicialización de políticas educativas ya definidas, pero no implementadas, a los estudiantes sordos en municipios del Estado de São Paulo, a partir del levantamiento de decisiones dictadas por el Tribunal de Justicia de São Paulo, en el período de 2005 a 2018. En posesión de los nueve resumos de las acciones, fue concebido que en cinco de ellas la tónica de los depoentes fue la garantía del derecho de la presencia del profesional Traductor e Intérprete de Lengua Brasileña de Señales (TILS) en el proceso de escolarización de estudiantes sordos. Se observó que las sentencias consolidaron la oferta del TILS como un derecho de este aludido, y fueron rápidamente atendidas en primera instancia. A pesar de la legislación vigente, la búsqueda por la efectividad de un derecho proclamado, pero no cumplido, fue ejecutada a través de la judicialización.

Palabras clave: Legalización. Educación de sordos. Derecho a la educación.

\footnotetext{
${ }^{1}$ Submetido em: 22 out. 2018 - Aceito em: 20 fev. 2019 - Publicado em: 05 nov. 2019.

${ }^{2}$ Universidade Estadual de Campinas (UNICAMP) - E-mail: csigolo@ gmail.com

${ }^{3}$ Universidade Estadual de Campinas (UNICAMP) - E-mail: anaelisasqa@ gmail.com
} 


\section{Introdução}

A Constituição Federal do Brasil de 1988 (CF/1988) (BRASIL, 1988), o Estatuto da Criança e do Adolescente (ECA) de 1990, a Lei 8.069/1990 (BRASIL, 1990) e a Lei de Diretrizes e Bases da Educação Nacional de 1996 (LDBEN) - Lei 9.394/1996 (BRASIL, 1996) declaram os deveres do Estado para a garantia do direito à educação para todos.

No que tange às pessoas com deficiência, o Atendimento Educacional Especializado (AEE) é garantia constitucional e, conforme o Artigo 208, Inciso III da CF/1988 (BRASIL, 1988), deve ocorrer, preferencialmente, na rede regular de ensino.

O documento Política Nacional de Educação Especial na Perspectiva da Educação Inclusiva (BRASIL, 2008, p. 1) entende os processos educacionais inclusivos como "uma ação política, cultural, social e pedagógica desencadeada em defesa do direito de todos os alunos de estarem juntos, aprendendo e participando sem nenhum tipo de discriminação". Pautada na perspectiva dos direitos humanos, que "conjuga igualdade e diferença como valores indissociáveis", o documento compreende que as ações educacionais devam superar a lógica da exclusão dentro e fora da escola (BRASIL, 2008, p. 1).

No que se refere aos estudantes surdos, a Lei Federal $n^{\circ} 13.005 / 2014$, que institui o Plano Nacional de Educação (PNE) 2014-2024 (BRASIL, 2014), prevê ao surdo optar por três modelos de escolarização: escolas bilíngues ${ }^{\mathrm{i}}$, classes bilíngues em escolas regulares e escolas regulares, em que o ensino é ministrado em português, com apoio de tradutor e de intérprete de Língua Brasileira de Sinais (Libras) e AEE no contraturno. Todavia, conforme atentam Câmara e Souza (2017), apesar desse instrumento jurídico qualificar as escolas e classes bilíngues Libras-Português como modalidades legítimas de escolarização das pessoas surdas, na prática os estudantes surdos são inseridos em escolas regulares. Bär, Santos e Souza (2017) complementam que essa falta de garantia se dá em razão do Ministério da Educação priorizar o repasse dos recursos provenientes do Fundo de Manutenção e Desenvolvimento da Educação Básica e de Valorização dos Profissionais da Educação (Fundeb) às prefeituras e estados que adotam a educação inclusiva com AEE no contraturno (BRASIL, 2011).

É válido ressaltar que a atual política educacional inclusiva adotada pelos municípios e estados deve ainda dialogar com outros dois documentos que dão oficialidade à Libras: a Lei Federal no 10.436 de 2002 (BRASIL, 2002), que reconhece a Libras "como meio legal de comunicação e expressão" dos surdos (Artigo $1^{\circ}$ ) e sua regulamentação pelo Decreto n 5.626 de 2005 (BRASIL, 2005) que, em seu Artigo 22, prevê a inserção de profissionais específicos para atuarem junto aos surdos no contexto educacional. No referido Decreto se lê:

Art. 22. As instituições federais de ensino responsáveis pela educação básica devem garantir a inclusão de alunos surdos ou com deficiência auditiva, por meio da organização de: I - escolas e classes de educação bilíngue, abertas a alunos surdos e ouvintes, com professores bilíngues, na educação infantil e nos anos iniciais do ensino fundamental; II - escolas bilíngues ou escolas comuns da rede regular de ensino, abertas a alunos surdos e ouvintes, para os anos finais do ensino fundamental, ensino médio ou educação profissional, com docentes das diferentes áreas de conhecimento, cientes da singularidade linguística dos alunos surdos, 
bem como com a presença de tradutores e intérpretes de Libras - língua portuguesa.

$\S 1^{\circ}$ São denominadas escolas ou classes de educação bilíngue aquelas em que a Libras e a modalidade escrita da língua portuguesa sejam línguas de instrução utilizadas no desenvolvimento de todo o processo educativo (BRASIL, 2005, grifo nosso).

Além de tratar sobre a importância do tradutor e intérprete de Libras (TILS) nos vários contextos educacionais dos estudantes surdos, o Decreto 5.626/2005 (BRASIL, 2005), em seu Capítulo 5, Artigo 17, menciona a necessidade de formação do TILS por meio de curso superior de Tradução e Interpretação, com habilitação em Libras-Língua Portuguesa.

Importa destacar que a profissão de TILS foi regulamentada pela Lei Federal $\mathrm{n}^{\circ}$ 12.319/2010 (BRASIL, 2010). Este documento legal prevê:

\footnotetext{
Art. $2^{\circ} \mathrm{O}$ tradutor e intérprete terá competência para realizar interpretação das 2 (duas) línguas de maneira simultânea ou consecutiva e proficiência em tradução e interpretação da Libras e da Língua Portuguesa. $[\ldots]$

Art. $7^{\circ} \mathrm{O}$ intérprete deve exercer sua profissão com rigor técnico, zelando pelos valores éticos a ele inerentes, pelo respeito à pessoa humana e à cultura do surdo e, em especial:

$[\ldots]$

VI - pelo conhecimento das especificidades da comunidade surda (BRASIL, 2010).
}

Já a Lei Brasileira de Inclusão da Pessoa com Deficiência (Estatuto da pessoa com deficiência) - Lei Federal $n^{\circ} 13.146 / 2015$ (BRASIL, 2015), entre outras medidas, estabeleceu aos surdos o direito à língua de sinais, como mecanismo de acessibilidade, nas esferas midiáticas, sociais, educativas, na área da saúde, entre outras.

Apesar da legislação vigente, as condições linguísticas e culturais do alunado surdo muitas vezes não são atendidas. Tais direitos proclamados, quando não cumpridos, são buscados na Justiça pelos estudantes surdos ou seus responsáveis, pautados na CF/1988, em seu Artigo 5, inciso XXXV, que afirma que "a lei não excluirá da apreciação do Poder Judiciário lesão ou ameaça a direito" (BRASIL, 1988).

Para Cury e Ferreira (2010, p. 77), o "Poder Judiciário passou a ter mais funções significativas na efetivação dos direitos legais, estabelecendo uma nova relação com a educação, a Judicialização da Educação", referida pelos autores como "a intervenção do Poder Judiciário nas questões educacionais em vista da proteção desse direito até mesmo para se cumprir as funções constitucionais do Ministério Público e outras instituições legitimadas".

Sob as condições relatadas, o presente artigo buscou analisar os encaminhamentos referentes à judicialização de políticas educacionais já previstas e definidas, mas não implementadas, aos estudantes surdos em municípios do Estado de São Paulo. A discussão dos casos recuperados se pautou a partir do levantamento realizado em junho de 2018 de decisões proferidas pelo Tribunal de Justiça de São Paulo (TJ-SP) ${ }^{\mathrm{ii}}$, no período de 2005 a 2018, dialogando com a legislação que trata dos processos educacionais dos sujeitos surdos e com a literatura que discorre a expansão da atuação do Poder Judiciário em busca da efetivação do direito à educação. Para tanto, a metodologia adotada tratou-se de uma pesquisa 
bibliográfica e documental a partir de uma discussão dos principais marcos jurídicos (leis e decretos), de revisão de literatura e da análise das decisões judiciais com relação às demandas do direito à educação de surdos. $\mathrm{O}$ recorte institucional da pesquisa teve o TJ-SP como órgão judicial escolhido, que possui as decisões judiciais publicadas em sítio eletrônico disponíveis ao público. O início do recorte temporal foi definido em virtude do ano de publicação do Decreto $n^{\circ} 5.626 / 2005$ que, conforme apresentado anteriormente, prevê que as instituições de ensino devem assegurar, em todas as etapas da educação, atendimento diferenciado aos alunos surdos, além de profissionais como professor ou instrutor de Libras e tradutor e intérprete de Libras (BRASIL, 2005).

Para a seleção das ementas dos processos judiciais, os descritores "surdez", "deficiência auditiva", "educação" e "Libras" foram utilizados para a busca ampliada das ações existentes no sítio eletrônico do TJ-SP no banco de dados "Consultas de Jurisprudência"iii, considerando que os descritores supramencionados tiveram como base o objeto de estudo do presente trabalho. As decisões analisadas consistem em acórdãos que tratam de ações individuais e de ações coletivas (Ações Civis Públicas) ${ }^{\mathrm{i}}$, proferidas em diferentes comarcas do Estado de São Paulo. A análise foi debruçada na produção bibliográfica jurídica e educacional sobre as temáticas evidenciadas nas decisões judiciais.

\section{Análise de dados e discussão}

Na pesquisa realizada no sítio eletrônico do TJ-SP foram encontradas nove ementas ${ }^{\mathrm{v}}$ de decisões judiciais a partir dos descritores supracitados versando sobre os direitos dos sujeitos surdos, as quais foram categorizadas por temáticas surgidas a partir do próprio conteúdo dessas. Foram identificadas quatro categorias, conforme exposto na tabela a seguir.

Tabela 1. Categorização das ementas

\begin{tabular}{lcc}
\hline \multicolumn{2}{c}{ Temas } & Números de decisões \\
\hline $\begin{array}{l}\text { Disponibilização de } \\
\text { educacional }\end{array}$ & 05 \\
$\begin{array}{l}\text { Disponibilização de Intérprete de Libras para obtenção de } \\
\text { Carteira Nacional de Habilitação }\end{array}$ & 02 \\
Concessão de benefício de amparo assistencial & 01 \\
Mandado de segurança - nomeação em concurso público & 01
\end{tabular}

Fonte: Elaborado pelas autoras a partir de banco de dados da pesquisa.

Em relação às decisões do TJ-SP envolvendo a efetivação das políticas públicas para a educação de surdos após a promulgação do Decreto 5.626/2005 (BRASIL, 2005), a análise das ementas dos nove documentos localizados evidenciou o uso do Poder Judiciário para a requisição do profissional TILS como demanda presente em cinco processos do conjunto encontrado $(n=5)^{\text {vi }}$ conforme visualizado no quadro abaixo. O número real do processo foi substituído por uma numeração sequencial para facilitar a organização e visualização. Cabe 
aqui destacar que todos os acórdãos julgados no período analisado estão disponíveis no sítio eletrônico do TJ-SP, que permite a seleção do tipo de decisão que se deseja consultar.

Quadro 1. Resumo das decisões judiciais por categorias das ementas

\begin{tabular}{|c|c|c|}
\hline Processo no & Categorização da Ementa & Decisão \\
\hline 1 & $\begin{array}{l}\text { Disponibilização de Intérprete de Libras } \\
\text { para estudante surda matriculada na rede } \\
\text { municipal de ensino. }\end{array}$ & $\begin{array}{l}\text { "Ofertar intérprete em Libras para o } \\
\text { acompanhamento da autora na rede pública } \\
\text { municipal de ensino" (SÃO PAULO, 2014a, p. } \\
\text { 4). }\end{array}$ \\
\hline 2 & $\begin{array}{l}\text { Disponibilização de Intérprete de Libras } \\
\text { para estudante surda matriculada na rede } \\
\text { municipal de ensino e oferta de curso de } \\
\text { Libras por profissional capacitado para a } \\
\text { estudante. }\end{array}$ & $\begin{array}{l}\text { "Condenar o requerido a oferecer à criança um } \\
\text { curso de Libras e, ainda, a disponibilizar um } \\
\text { professor intérprete qualificado na mesma } \\
\text { língua de sinais para acompanhá-la, em sala de } \\
\text { aula regular" (SÃO PAULO, 2014b, p. 2). }\end{array}$ \\
\hline 3 & $\begin{array}{l}\text { Disponibilização de intérprete de Libras } \\
\text { para estudante surdo matriculado em } \\
\text { Instituição de Ensino Superior. }\end{array}$ & $\begin{array}{l}\text { "Determinação que se providencie a contratação } \\
\text { de intérprete de Libras" (SÃO PAULO, 2014c, } \\
\text { p. 9). }\end{array}$ \\
\hline 4 & $\begin{array}{l}\text { Disponibilização de Intérprete de Libras } \\
\text { para estudante surdo matriculado na rede } \\
\text { estadual de ensino. }\end{array}$ & $\begin{array}{l}\text { "Ofertar intérprete em Libras para o } \\
\text { acompanhamento do autor na rede pública } \\
\text { estadual de ensino" (SÃO PAULO, 2014d, p. } \\
\text { 3). }\end{array}$ \\
\hline 5 & $\begin{array}{l}\text { Ação Civil Pública: garantia de oferta de } \\
\text { Intérprete em Libras a todas as salas de } \\
\text { aula da rede municipal de educação em } \\
\text { que houver aluno portador de deficiência } \\
\text { auditiva. }\end{array}$ & $\begin{array}{l}\text { "Ofertar intérprete de Libras para atuar na rede } \\
\text { pública municipal de ensino" (SÃO PAULO, } \\
\text { 2012, p. 4). }\end{array}$ \\
\hline
\end{tabular}

Fonte: Elaborado pelas autoras a partir de banco de dados da pesquisa.

Os demais processos digitais $(n=4)$ : Processo $n^{\mathbf{0}}$ 6, que trata de concessão de segurança a fim de que a depoente (ouvinte) seja convocada, nomeada e empossada em concurso público do Estado para cargo de Professor de Educação Básica II para atuar em Educação Especial de alunos com deficiência auditiva (SÃO PAULO, 2018); Processo no 7 , referente a concessão de benefício de amparo assistencial a uma pessoa surda (SÃO PAULO, 2016); Processo $\mathbf{n}^{\mathbf{0}} \mathbf{8}$, cujos autores são cinco deficientes auditivos que solicitam a disponibilização de intérprete de Libras para obtenção de Carteira Nacional de Habilitação (SÃO PAULO, 2015); Processo $\mathbf{n}^{\mathbf{0}}$ 9, em que o depoente solicita que o órgão de trânsito disponibilize profissional habilitado na tradução da prova escrita para a Libras, para a realização da prova escrita e para obtenção de Carteira Nacional de Habilitação (SÃO PAULO, 2013), que referiram-se a demandas em demais âmbitos, para além do educacional, não serão explorados neste artigo.

A discussão contida nos autos do Processo $\mathbf{n}^{\mathbf{0}} \mathbf{1}$ referiu-se sobre a pretensão da responsável pela depoente, estudante surda matriculada na rede municipal de um município do Estado de São Paulo quanto a disponibilização do profissional TILS à representada, sendo que o pedido foi julgado procedente. Em sede de Apelação/Reexame necessário, em que a apelante foi a prefeitura do Município e a apelada foi a responsável pela estudante surda, a 
decisão foi mantida, adotando um posicionamento favorável em prol da efetivação do direito da depoente.

Conforme destacam Lacerda, Santos, Lodi e Gurgel (2016), é também no Decreto 5.626/2005 (BRASIL, 2005) que podem ser encontradas orientações para se garantir o direito à educação pelos estudantes surdos. Nas palavras das autoras:

\begin{abstract}
para as séries iniciais (Educação Infantil e anos iniciais do Ensino Fundamental), as crianças devem ter a oportunidade de acesso aos conteúdos escolares em sua língua de domínio, ou seja, em Libras, com a presença de professor bilíngue; e para os anos finais do Ensino Fundamental e Ensino Médio, o processo educacional deve ser realizado com a presença de tradutores e intérpretes de Libras em cada sala de aula onde houver um aluno surdo usuário de Libras matriculado, além da necessidade dos professores responsáveis pelas diversas áreas de conhecimento considerarem a singularidade linguística dos alunos, considerando que nas classes haverá a presença de um profissional a mais (tradutor e intérprete de Libras, cujo papel e formas de atuação nem sempre são conhecidas) e que os alunos terão uma relação com a Língua Portuguesa de forma bastante diferenciada dos alunos ouvintes (LACERDA et al. 2016, p. 16).
\end{abstract}

Em relação ao objeto de análise do Processo no 2, foi julgada procedente a Ação Civil Pública ajuizada pelo Ministério Público que condenou um município do Estado de São Paulo a "oferecer à estudante surda um curso de Libras e disponibilizar um professor intérprete qualificado na mesma língua de sinais, para acompanhá-la, em rede regular" (SÃO PAULO, 2014b, p. 2, grifo nosso).

Lins e Nascimento (2017, p. 14) reforçam que o papel da escola vai muito além das questões de acesso linguístico: "sem a apropriação de uma primeira língua não há possibilidade de uma aprendizagem significativa, nos anos iniciais de formação". As autoras reiteram que "aprender uma língua, garante a formação de uma identidade autônoma aos surdos e possibilita que se reconheçam como seres humanos completos”.

O Processo $\mathbf{n}^{\mathbf{0}} 3$ foi de autoria de um estudante surdo de uma Instituição de Ensino Superior (IES), que solicitou a contratação de um profissional intérprete de Libras. O depoente referiu que no primeiro semestre letivo foi auxiliado por uma colega de curso "que servia como intérprete em troca de uma bolsa de estudos concedida pela própria ré" e que essa circunstância "não possibilitava a efetiva tradução simultânea das matérias ministradas, mas apenas repassar conhecimentos ao autor quando do término das aulas" (SÃO PAULO, 2014c, p. 4).

Martins e Napolitano (2017) abordaram questões legais e judiciais que favoreceram e inibiram o acesso e permanência de estudantes surdos na educação superior. Os autores verificaram que nem todas as universidades estavam preparadas para o acolhimento de estudantes surdos e apontaram que algumas IES sanaram a ausência do profissional TILS com apoios, em forma de bolsas de estudos ou de monitoria aos estudantes universitários com conhecimento em Libras, para exercício desta função aos surdos, providência considerada paliativa, pois não atende o determinado na legislação, que prevê a contratação do TILS, em consonância com o Decreto 5626/2005 (BRASIL, 2005). Os autores trouxeram à tona as dificuldades dos estudantes surdos nesse contexto ao 
observar que os que deveriam se responsabilizar por defender os direitos dos cidadãos, por reconhecimento de causa em decorrência das especificidades que envolvem a temática abordada - as políticas linguísticas em favor do cumprimento da educação bilíngue para surdos universitários - são os mesmos que colocam em risco os direitos conquistados por este mesmo grupo, quando lhes são negados a contratação de profissionais qualificados para a prática de interpretação de Libras/Português nas ações ofertadas pelas IES, condição necessária à formação do surdo nesta etapa de ensino (MARTINS; NAPOLITANO, 2017, p. 118).

Ainda em relação à acessibilidade e permanência de estudantes surdos no ensino superior, Lins e Nascimento (2017) verificaram que no período de 2005 a 2015, 95 candidatos se autodeclararam deficientes auditivos ao vestibular da Universidade Estadual de Campinas (UNICAMP), mas somente 2 ingressaram. As autoras evidenciaram a insuficiente oferta do profissional TILS para a realização da prova do vestibular. Porém, como medida afirmativa, as autoras destacaram que no Programa de Pós-Graduação da Faculdade de Educação da mesma Universidade são utilizadas formas de avaliação que respeitam as singularidades linguísticas dos surdos, garantindo o acesso e permanência desses estudantes.

A disponibilização do profissional TILS também foi discutida nos autos do Processo $\mathbf{n}^{\mathbf{0}}$ 4, proposta por um estudante surdo da Rede Estadual de Ensino contra a Fazenda Pública do Estado de São Paulo. A sentença julgou procedente a ação, mas "inconformada", a Fazenda "sustentou ter dificuldades no atendimento desta obrigação, diante da escassez de servidores para essa função (Professor Intérprete)" (SÃO PAULO, 2014d, p. 3). O julgado foi favorável ao estudante surdo.

Por sua vez, o Processo no 5 tratou-se de uma Ação Civil Pública que versava sobre a garantia de oferta de Intérprete de Libras em todas as salas de aula da Rede Municipal de Educação em que houvesse algum estudante surdo, e foi prontamente atendida.

Nesse contexto, Santos et al. (2018) identificaram os motivos de judicialização de uma política pública referente ao tratamento integral dispensado a todas as pessoas com Transtorno do Espectro do Autismo (TEA) residentes no Estado de São Paulo, que já deveria estar assegurada a essa população, a partir da análise de uma Ação Civil Pública. Os autores constataram que apesar da legislação vigente, existia uma grande distância entre as leis e a efetivação de um direito, sendo que o Poder Judiciário passou a ser uma esfera tanto de apelação como de poder imperativo de execução.

Os acórdãos que trataram da atuação do Poder Judiciário quanto às decisões judiciais relacionadas à garantia de TILS na escolarização de pessoas surdas tiveram como recorte legal especialmente a CF/1988 (BRASIL, 1988), a Lei 8.069/1990 (BRASIL, 1990), a Lei 9.394/1996 (BRASIL, 1996), a Lei 10.436/2002 (BRASIL, 2002) e o Decreto 5.626/2005 (BRASIL, 2005).

Cabe retomar, neste momento, a noção de políticas públicas educacionais apresentada por Assis (2012), que a entende como fruto das discussões legislativas e promulgação de suas normas, dos atos administrativos e das decisões políticas, ficando a cargo do Poder Judiciário e do Ministério Público a efetivação da política. Assis e Vedovato (no prelo) explicam que as leis que cuidam de políticas públicas estão diretamente vinculadas ao propósito da busca do bem comum, para além da garantia de regras de convivência. 
A esse respeito, Duarte (2004) destaca que, o sistema educacional deve proporcionar diferentes oportunidades de desenvolvimento e promover valores como o respeito aos direitos humanos, em condições de liberdade e dignidade, considerando que o direito à educação não deve se reduzir ao direito do indivíduo em cursar o ensino fundamental para alcançar melhores oportunidades de emprego. Nessa perspectiva, Assis e Rus Perez (2013) referem que assumir um conceito amplo de educação é compreender que o direito à educação como direito social é uma das dimensões formadoras da Dignidade da Pessoa Humana.

Porém, em três décadas da CF/1988 (BRASIL, 1988), a expansão do direito dos estudantes surdos incluídos na rede regular de ensino a contarem com a presença do TILS vem ocorrendo, em alguns casos, por meio da judicialização.

Assis (2012) compreende a judicialização como o ato de levar ao conhecimento do juiz o descompasso entre o direito (right) estabelecido na lei (law) e sua efetivação na sociedade. Nesta direção, a previsão de veiculação de conflitos de interesses metaindividuais por meio de ações judiciais, como a ação civil pública, o mandado de injunção, o mandado de segurança coletivo e a ação popular, fez com que essas categorias assumissem novas dimensões (DUARTE, 2004), já que nos últimos anos a quantidade de ações com a temática judicialização de políticas públicas tem aumentado significativamente (ASSIS, 2015).

Cury e Ferreira (2010, p. 81) referem que o fenômeno da judicialização da educação é verificado diante da ocorrência de fatores que impliquem na ofensa a esse direito, a saber: "(a) mudanças no panorama legislativo; (b) reordenamento das instituições judicial e escolar; (c) posicionamento ativo da comunidade na busca pela consolidação de direitos sociais". Logo, a judicialização tem sido uma estratégia necessária a grande número de famílias para alcançar a efetivação do direito à educação (SILVEIRA, 2011; 2012).

De posse das supracitadas ementas, foi concebido que a tônica dos depoentes foi colocar em evidência a garantia do direito de os estudantes surdos à presença do TILS em seu processo de escolarização. As análises do Judiciário quanto às ações aqui apresentadas versando sobre as demandas envolvendo a disponibilização de TILS no âmbito educacional consolidaram o dever do Estado, com responsabilidade dos municípios, do Estado ou da Instituição de Ensino Superior, ao decidirem que a presença desse profissional se constituiu um direito dos estudantes surdos ou de seus responsáveis em exigir seu cumprimento perante o Judiciário, e foram prontamente atendidas em primeira instância.

A esse respeito, Silveira (2012), ao analisar decisões do TJ-SP sobre o direito de crianças e adolescentes à educação, destacou que as ações com pedidos individuais foram atendidas com mais facilidade, mas quando foram solicitadas medidas para ampliação do atendimento ou para criação de políticas, o Tribunal não se mostrou coeso para a concessão, debruçado no argumento de impossibilidade de interferência do Judiciário na condução de políticas públicas e na questão orçamentária.

$\mathrm{Na}$ esteira de tais esforços, Silveira (2017) buscou compreender as possibilidades e os limites do processo de judicialização, para a expansão do direito à educação ao investigar a atuação do Ministério Público e Poder Judiciário no estado do Paraná. A autora identificou 
que a maioria das ações foram ingressadas visando uma demanda individual, tendo-se um pequeno percentual de ações coletivas.

Considerando a judicialização de uma política pública, Assis e Rus Perez (2013) discutiram demandas por vagas na educação infantil pública para crianças de 0 a 3 anos e relataram que, apesar do Poder Judiciário efetivar um direito individual estabelecido (vaga escolar) para um problema coletivo (falta de escolas), a solução individualizada (criação de uma vaga em uma instituição de ensino) não efetivou um direito, pois sua concretização tem criado outros problemas (superlotação nas creches). "O direito à educação é claro e pleno, não pode e nem deve ser flexibilizado, correndo o risco de transformar-se num crime contra a dignidade da pessoa humana" (ASSIS; RUS PERES, 2013, p. 168).

Oliveira, Silva e Merchetti (2018) analisaram as estratégias adotadas pela Prefeitura de São Paulo diante dos litígios envolvendo vagas em creche, a fim de verificar a influência da estratégia judicial nas políticas públicas de educação do município. A partir do levantamento de dados junto à Secretaria Municipal de Educação de São Paulo, os autores apresentaram que a demanda por vagas em "creches contava com aproximadamente 75 mil crianças na chamada "fila"” (OLIVEIRA et al. 2018, p. 660, aspas do original). Os autores afirmam que "tomando o caso da cidade de São Paulo como referência, podemos afirmar que a agenda acabou impactada pelas decisões judiciais, seja por obrigar os governos a fazer mais que fariam, seja por ditar o rumo de sua implementação" (OLIVEIRA et al. 2018, p. 666).

Como contraponto temos o estudo de Amaral e Bernardes (2018), que analisaram o movimento de judicialização da educação inclusiva no âmbito da educação básica no estado de Goiás. As autoras encontraram 13 decisões em sítio eletrônico público do Tribunal Regional Federal $1^{a}$ Região (TRF1) e Tribunal de Justiça do estado de Goiás (TJ-GO) referentes à questão da educação como direito e apontaram que nessas decisões analisadas foram evidenciadas situações de pessoas com deficiência que em algum momento necessitaram de uma providência do poder público local para fornecer um serviço especial no âmbito escolar, mas todas elas já asseguradas na CF/1988, Lei n 7.853/1989 (BRASIL, 1989) e LDBEN/1996. As autoras evidenciaram uma busca mínima pelo Judiciário para questões referentes à educação inclusiva, "o que leva a compreensão de que tem ocorrido a garantia de direitos dos deficientes, ou ainda que as minorias podem não ter ciência de seus direitos e estarem silenciadas pelas circunstâncias" (AMARAL; BERNARDES, 2018, p. 171).

Ilustram-se tais situações as considerações de Assis (2012), que o comportamento das ações judiciais não tem efetivado o direito à educação, mas ferido o princípio da dignidade da pessoa humana, pois não se preocupa em resolver o problema coletivamente e afirma que "infelizmente, as ações judiciais têm causado maior prejuízo à sociedade do que atuado de forma a contribuir com uma avaliação da política, ou efetivação adequada do direito à educação" (ASSIS, 2016, p. 275). No caso da oferta do profissional TILS para os estudantes surdos, os dispositivos legais que garantem esse direito representam uma conquista para as comunidades surdas, mas defende-se que esses agentes tenham uma formação inicial e continuada que os capacite para suas atribuições quanto à qualidade e êxito na educação de 
surdos, para que sua inserção em sala de aula não se reduza somente à determinação de uma judicialização.

\section{Conclusão}

Apesar da legislação vigente, a procura pelo Judiciário nas ementas aqui discutidas foi, em sua maioria, a busca pela efetivação de um direito. Nesta esteira de distanciamento entre as leis e a efetivação de um direito, quando as garantias legais não correspondem à realidade dos serviços que lhes são oferecidos pelo poder público, é evidenciada maior presença de demandas individuais em contraposição às coletivas, com soluções individualizadas, sendo esta, nomeada por Assis e Rus Perez (2013), a mais nova relação estabelecida entre direito à educação e Poder Judiciário.

Nas ementas expostas se manteve explícita a necessidade da presença do profissional TILS na área da Educação de Surdos, mas cabe apontar, em consonância com Silveira (2011), que as análises dos processos judiciais não são parâmetros para avaliar o grau de injustiça, pois grande parcela da população não conhece seus direitos e/ou o ritual para reivindicá-los.

É válido ressaltar que a devida assunção de um direito que é de todos os estudantes surdos pode ainda estar sendo indeferida ou desrespeitada para muitos deles, e que somente a oferta do profissional TILS parece ser insuficiente para permitir seu ingresso e permanência no âmbito escolar. Conforme alertam Lins e Nascimento (2017), o direito a uma educação que assuma as particularidades linguísticas dos estudantes surdos e que garanta o fortalecimento das identidades surdas não pode ser negado. Para tal torna-se necessário dar visibilidade a esse alunado, independente da sua condição auditiva - traço classificatório que por muitas vezes ainda encara esses sujeitos pelo viés de deficiência, e que a inserção do TILS no âmbito educacional, não se reduza a uma determinação judicial. Nesta direção, compactua-se com Assis (2016) que evidencia que a discussão de políticas públicas educacionais extrapola os universos jurídicos e pedagógicos, de forma a não perder o objetivo, que é a melhor efetivação do direito à educação (neste caso, à educação dos sujeitos surdos), diante de questões secundárias.

\section{Referências}

AMARAL, Claudia Tavares do; BERNARDES, Maria Francisca Rita. Judicialização da Educação Inclusiva: uma análise do contexto do estado de Goiás. Revista Tempos e Espaços em Educação, São Cristóvão, Sergipe, v. 11, n. 25, p. 173-188, abr./jun. 2018. Disponível em: https://seer.ufs.br/index.php/revtee/article/view/6875/pdf. Acesso em: 22 out. 2018.

ASSIS, Ana Elisa Spaolonzi Queiroz. Direito à Educação e Diálogo entre Poderes. 2012. 271 f. Tese (Doutorado em Educação), Faculdade de Educação, Universidade Estadual de Campinas, Campinas, 2012. 
ASSIS, Ana Elisa Spaolonzi Queiroz. Judicialização de avaliações em larga escala: breves considerações. In: JEFREY, Débora Cristina (org.). Política e Avaliação Educacional: interfaces com a epistemologia. 1 ed. Curitiba, PR: CRV, 2015. p. 201-220.

ASSIS, Ana Elisa Spaolonzi Queiroz. O Poder Judiciário Brasileiro: um novo âmbito de decisões das políticas educacionais? In: BEHARES, Luís Ernesto; GIMÉNEZ, Raumar Rodrígues (org.). VII Encontro Internacional de Investigadores de Políticas Educativas. 1 ed. Montevideo: Asociación de Universidades Grupo Montevideo (AUGM), 2016, v. 1, p. 271-276. Disponível em: https://seer.ufrgs.br/Poled/article/view/69710/39245. Acesso em: 20 dez. 2018.

ASSIS, Ana Elisa Spaolonzi Queiroz; RUS PEREZ, José Roberto. Justiça social e política educacional: Extensão das vagas escolares na educação infantil. In: Revista de Educação PUC-Campinas, Campinas, SP, v. 18, p. 161-170, 2013. Disponível em:

http://periodicos.puc-campinas.edu.br/seer/index.php/reveducacao/article/view/2025. Acesso em: 17 out. 2018.

ASSIS, Ana Elisa Spaolonzi Queiroz; VEDOVATO, Luís Renato. Interpretação Jurídica: considerações para a análise de políticas públicas (no prelo).

BÄR, Eliana Cristina; SANTOS, Samuel Alves dos; SOUZA, Regina Maria de. Os reflexos das reformas da década de 90 na política brasileira de educação bilíngue para surdos. In: OLIVEIRA, Gilvan Muller de; RODRIGUES, Luana Ferreira (org.). Atas do VIII Encontro Internacional de Investigadores de Políticas Linguísticas. Florianópolis: UFSC Universidade Federal de Santa Catarina e AUGM Associação de Universidades Grupo Montevidéu - Núcleo Educação para Integração, 2017, p. 208-216.

BRASIL. Constituição da República Federativa do Brasil. Brasília, DF: Senado Federal, 1988. Disponível em: http://www.planalto.gov.br/ccivil_03/leis/18069.htm. Acesso em: 28 maio 2018.

BRASIL. Decreto n. 5.626, de 22 de dezembro de 2005. Regulamenta a Lei n. 10.436, de 24 de abril de 2002, que dispõe sobre a Língua Brasileira de Sinais - Libras, e o art. 18 da Lei n. 10.098, de 19 de dezembro de 2000. Diário Oficial da República Federativa do Brasil.

Brasília, DF. Disponível em: http://www.planalto.gov.br/ccivil_03/_ato2004-

2006/2005/decreto/d5626.htm. Acesso em: 28 maio 2018.

BRASIL. Decreto no 7.611, de 17 de novembro de 2011. Dispõe sobre a educação especial, o atendimento educacional especializado e dá outras providências. Diário Oficial da República Federativa do Brasil. Brasília, DF. Disponível em: http://www.planalto.gov.br/ccivil_03/_ato2011-2014/2011/decreto/d7611.htm. Acesso em: 28 maio 2018.

BRASIL. Lei $\mathbf{n}^{\mathbf{0}} \mathbf{7 . 8 5 3}$, de 24 de outubro de 1989. Dispõe sobre o apoio às pessoas portadoras de deficiência, sua integração social, sobre a Coordenadoria Nacional para integração da Pessoa Portadora de Deficiência - Corde, institui a tutela jurisdicional de interesses coletivos ou difusos dessas pessoas, disciplina a atuação do Ministério Público, define crimes e dá outras providências. Brasília: DF. Disponível em: http://www.planalto.gov.br/ccivil_03/Leis/L7853.htm. Acesso em: 22 out. 2018. 
BRASIL. Lei no 8.069, de 13 de julho de 1990. Dispõe sobre o Estatuto da Criança e do Adolescente e dá outras providências. Diário oficial da República Federativa do Brasil. Brasília: DF. Disponível em: http://www.planalto.gov.br/ccivil_03/leis/18069.htm. Acesso em: 28 maio 2018.

BRASIL. Lei $\mathbf{n}^{\mathbf{0}}$ 9.394, de 20 de dezembro de 1996. Estabelece as diretrizes e bases da educação nacional. Diário oficial da República Federativa do Brasil. Brasília: DF. Disponível em: http://www.planalto.gov.br/ccivil_03/LEIS/19394.htm. Acesso em: 28 maio 2018.

BRASIL. Lei no 10.436, de 24 de abril de 2002. Dispõe sobre a Língua Brasileira de Sinais Libras e dá outras providências. Diário oficial da República Federativa do Brasil. Brasília: DF. Disponível em: http://www.planalto.gov.br/ccivil_03/leis/2002/110436.htm. Acesso em: 28 maio 2018.

BRASIL. Lei no 12.319, de 01 de setembro de 2010. Regulamenta a profissão de Tradutor e Intérprete da Língua Brasileira de Sinais - LIBRAS. Diário Oficial da República Federativa do Brasil. Brasília: DF. Disponível: http://www.planalto.gov.br/ccivil_03/ato20072010/2010/lei/112319.htm. Acesso em: 28 maio 2018.

BRASIL. Lei no 13.005, de 25 de junho de 2014. Aprova o Plano Nacional de Educação PNE e dá outras providências. Diário Oficial da República Federativa do Brasil. Brasília: DF. Disponível: http://www.planalto.gov.br/ccivil_03/_ato2011-2014/2014/lei/113005.htm.

Acesso em: 28 maio 2018.

BRASIL. Lei no 13.146, de 06 de julho de 2015. Institui a Lei Brasileira de Inclusão da Pessoa com Deficiência (Estatuto da Pessoa com Deficiência). Diário Oficial da República Federativa do Brasil. Brasília: DF. Disponível em: http://www.planalto.gov.br/ccivil_03/_ato2015-2018/2015/lei/113146.htm. Acesso em: 28 maio 2018.

BRASIL. Política Nacional de Educação Especial na Perspectiva da Educação Inclusiva. Brasília: MEC/SEESP, 2008. Disponível em: http://portal.mec.gov.br/arquivos/pdf/politicaeducespecial.pdf. Acesso em: 28 maio 2018.

CÂMARA, Leandro Calbente; SOUZA, Regina Maria de. Das leis para a inclusão de surdos às (im)possibilidades de mudanças nas práticas escolares para a implantação da Educação Bilíngue no Brasil. In: LINS, Heloísa Andréa Matos; NASCIMENTO, Lilian Cristine Ribeiro; SOUZA, Regina Maria de (org.); SANTOS, Gildenir Carolino (Ed.). Ações Afirmativas para pessoas surdas no processo de escolarização. [e-book]. Campinas, SP: Biblioteca/UNICAMP, 2017. (Série Setembro Azul, 5). p. 47-64. Disponível em: http://www.bibliotecadigital.unicamp.br/document/?down=74330. Acesso em: 12 dez. 2018.

CURY, Carlos Roberto Jamil; FERREIRA, Luiz Antônio Miguel. Justiciabilidade no campo da educação. RBPAE, v. 26, n. 1, p. 75-103, jan./abr. 2010.

DUARTE, Clarice Seixas. Direito Público Subjetivo e Políticas Educacionais. São Paulo em Perspectiva: São Paulo, v. 18, n. 2, p. 113-118, 2004. Disponível em: http://www.scielo.br/pdf/spp/v18n2/a12v18n2.pdf. Acesso em: 17 out. 2018. 
LACERDA, Cristina Broglia Feitosa de et al. Educação Inclusiva Bilíngue para alunos surdos - pesquisa e ação em uma rede pública de ensino. In: LACERDA, Cristina Broglia Feitosa de; SANTOS, Lara Ferreira dos; MARTINS, Vanessa Regina de Oliveira (org.). Escola e diferença: caminhos para educação bilíngue de surdos. São Carlos: EDUFSCar, 2016. p. 13-28.

LINS, Heloísa Andréa Matos; NASCIMENTO, Lilian Cristine Ribeiro. Luta por reconhecimento: situando o debate em torno da ações afirmativas para pessoas surdas no processo de escolarização. In: LINS, Heloísa Andréa Matos; NASCIMENTO, Lilian Cristine Ribeiro; SOUZA, Regina Maria de (org.); SANTOS, Gildenir Carolino (Ed.). Ações Afirmativas para pessoas surdas no processo de escolarização. [e-book]. Campinas, SP: Biblioteca/UNICAMP, 2017. (Série Setembro Azul, 5). p. 11-20. Disponível em: http://www.bibliotecadigital.unicamp.br/document/?down=74330. Acesso em: 12 dez. 2018.

MARTINS, Sandra Eli Sartoreto de Oliveira; NAPOLITANO, Carlo José. Inclusão, acessibilidade e permanência: direitos de estudantes surdos à educação superior. Educar em Revista, Curitiba, v. 33, n. Esp. 3, p. 107-126, dez. 2017. Disponível em: http://www.scielo.br/pdf/er/nspe.3/0104-4060-er-03-107.pdf. Acesso em: 17 out. 2018.

OLIVEIRA, Vanessa Elias de; SILVA, Mariana Pereira da; MARCHETTI, Vitor. Judiciário e Políticas Públicas: o caso das vagas em creches na cidade de São Paulo. Educ. Soc., Campinas, v. 39, n. 144, p. 652-670, jul./set. 2018. Disponível em: http://www.scielo.br/pdf/es/v39n144/1678-4626-es-es0101-73302018176112.pdf. Acesso em: 14 dez. 2018.

SANTOS, Samuel Alves dos et al. Malabarismo com os Direitos dos Autistas: Judicialização e novas formas de Suplício. In: FARENZENA, Nalú; MACHADO, Maria Goreti Farias (org.). VIII Encontro Internacional de Investigadores de Políticas Educativas. Porto Alegre: UFRGS, 2018; Montevidéu: Associação de Universidades Grupo Montevidéu: 2018. p. 275-284. Disponível em: https://seer.ufrgs.br/Poled/article/view/88462. Acesso em: $20 \mathrm{dez}$. 2018.

SÃO PAULO. Processo no 0010996-59.2008.8.26.0428. Tribunal de Justiça de São Paulo, 2012.

SÃO PAULO. Processo n⿳0 3001844-59.2013.8.26.0101. Tribunal de Justiça de São Paulo, 2013.

SÃO PAULO. Processo no 1014832-18.2017.8.26.0554. Tribunal de Justiça de São Paulo, 2014a.

SÃO PAULO. Processo no 0000179-54.2014.8.26.0159. Tribunal de Justiça de São Paulo, 2014b.

SÃO PAULO. Processo no 0019661-96.2012.8.26.0566. Tribunal de Justiça de São Paulo, 2014c.

SÃO PAULO. Processo no 0011339-89.2013.8.26.0554. Tribunal de Justiça de São Paulo, 2014d. 
SÃO PAULO. Processo n ${ }^{0}$ 1005023-70-2014.8.26.0566. Tribunal de Justiça de São Paulo, 2015.

SÃO PAULO. Processo n⿳0 0004822-73-2008.8.26.0415. Tribunal de Justiça de São Paulo, 2016.

SÃO PAULO. Processo no 1000397-55.2018.8.26.0408. Tribunal de Justiça de São Paulo, 2018.

SILVEIRA, Adriana Dragone. Atuação do Tribunal de Justiça de São Paulo com relação ao direito de crianças e adolescentes à educação. Revista Brasileira de Educação, v. 17, n. 50, p. 353-497, maio/ago. 2012. Disponível em:

http://www.scielo.br/pdf/rbedu/v17n50/v17n50a06.pdf. Acesso em: 17 out. 2018.

SILVEIRA, Adriana Dragone. Judicialização para a efetivação do direito à educação básica. Jornal de Políticas Educacionais, n. 9, p. 30-40, jan./jun. 2011.

SILVEIRA, Adriana Dragone. Judicialização da Política Educacional: uma análise da atuação do Ministério Público e do Tribunal de Justiça do Paraná. Rev. Educ. Perspec., v. 8, n. 3, p. 309-327, set./dez. 2017.

SOUZA, Regina Maria de et al. Relatório do Grupo de Trabalho para analisar e propor a implantação da estrutura adequada para atender ensino de Libras e demais questões correlatas. In: LINS, Heloísa Andréa Matos; SOUZA, Regina Maria de; NASCIMENTO, Lilian Cristine Ribeiro (org.). Plano Nacional de educação e as políticas locais para implantação da educação bilíngue para surdos. Campinas, SP: Unicamp/FE. (Setembro Azul; 4), 2016, p. 2-28. Disponível em: http://www.bibliotecadigital.unicamp.br/document/?down=62805. Acesso em: 20 dez. 2018.

\section{Notas}

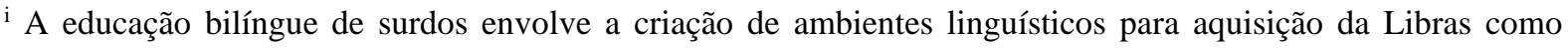
primeira língua (L1) por crianças surdas, no tempo de desenvolvimento linguístico esperado e similar ao das crianças ouvintes, e a aquisição do português como segunda língua (L2) (SOUZA et al. 2016).

ii O Tribunal de Justiça de São Paulo, considerado o maior Tribunal do mundo em volume de processos, tem como missão resolver conflitos da Sociedade, no âmbito de sua competência, para preservação dos direitos, por meio de julgamento de processos ou de métodos adequados. Disponível em: http://www.tjsp.jus.br/QuemSomos. Acesso em: 03 jun. 2018.

iii Disponível em: https://esaj.tjsp.jus.br/cjsg/consultaCompleta.do?f=1. Acesso em: 03 jun. 2018.

iv A Ação Civil Pública (art. 129, III CF/88), conforme ensina Assis (2012, p. 84-85) "vem como dever do Ministério Público para promover a ação de direitos coletivos e difusos entre outros, completamente convergente ao controle judicial de políticas públicas numa perspectiva de solicitação de ação do Poder Executivo em caso de demonstrar-se inerte e descomprometido com seus deveres constitucionais".

${ }^{\vee}$ Em consonância com as considerações feitas por Silveira (2011, p. 358) ao analisar decisões do TJ-SP sobre o direito de crianças e adolescentes à educação, de que "as decisões coletadas no âmbito desta pesquisa constituem-se de um conjunto ilustrativo, não podendo ser considerado uma amostra do que foi julgado pelo TJSP referente ao direito de crianças e adolescentes à educação", ressaltamos que as ementas apresentadas neste artigo não devem ser consideradas como correspondentes ao total de decisões julgadas pelo TJ-SP referente aos sujeitos surdos.

${ }^{\text {vi }} \mathrm{n}=$ número amostral.
} 


\section{Agradecimentos}

Ao Prof. Dr. Luís Renato Vedovato, pelas reflexões teóricas compartilhadas.

À Profa. Dra. Regina Maria de Souza e seu atual Grupo de Orientandos (Cristiane Maria da Silva, Eliana Cristina Bär, Leandro Calbente Câmara, Morena Dolores Patriota da Silva, Regiane Pinheiro Agrella, Samuel Alves dos Santos e Taísa Cristina França), pelos saberes partilhados e contribuições na pesquisa. 